\title{
Nerve Abscesses in Northern Nigeria
}

\author{
F. G. PRIESTMAN, M.в.B.s. \\ Medical Superintendent, Plateau Provincial Leprosy Settlement, Mongu, N. Nigeria
}

In view of the fact that the rarity of nerve abscesses in Africa is frequently commented upon, it may be of interest to report several patients seen in the last 4 years in Northern Nigeria, including 3 patients with multiple abscesses in cutaneous nerves.

Patient 1 -In October, 1964, a male patient aged 22, was admitted to this leprosarium in a very debilitated condition. He had had 6 months' treatment in a local out-patient clinic. He had numerous large lesions of the tuberculoid type, markedly hypopigmented, symmetrically distributed over the face, back and buttocks, and involving the major part of all 4 limbs. The edges of the lesions were very active, and there were some satellites, as well as some smaller individual lesions of the trunk and limbs. There was extensive nerve involvement, including both supra orbitals, right auricular, both ulnars, both radials, right median at the elbow and both popliteals. There was right partial wrist drop, and complete ulnar and median paralysis, obviously of long standing, with flattening of the whole hand. There was left ulnar and bilateral peroneal weakness. In addition to the above findings, this patient had 15 small 'abscesses' in cutaneous nerves. There were 5 in the left medial cutaneous nerve of the arm, 2 above and 3 below the elbow: 3 in the same nerve on the right side, 2 above and 1 below the elbow; 3 in the superficial peroneal nerve in the left lower

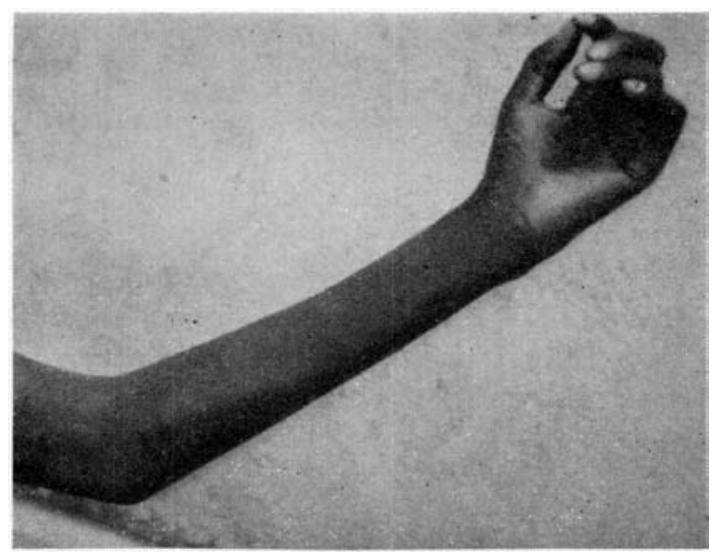

Multiple nerve 'abscesses' in superficial nerves. Three shown in medial antepradnal cutaneous nerve. Patient 1 leg; 2 in the superficial peroneal on the dorsum of the right foot; 1 in a small cutaneous nerve in the right calf; and the largest, in the sural nerve behind the right lateral malleolus. All except the last were about the size of a pea, and contained greyish gelatinous material, which was very tenacious. The last one, about 3 times the size of the others, contained frank pus. All were incised under local anaesthetic, evacuated, the wounds closed without drainage, and they healed rapidly.

The patient was treated with Ciba 1906 for 11 months, then with Dapsone. He was most cooperative with physiotherapy, and has full recovery of his left hand and both feet. There have been no new nerve complications.

\section{Patients 2 and 3 were seen in Bornu Province} while doing relief duties at the Provincial Leprosarium, Maiduguri.

Patient 2-A boy of 12 was admitted to the leprosarium in April, 1965, with low-resistant tuberculoid leprosy. There was one very large lesion involving most of the lower back, with a few satellite lesions, and a large lesion of the dorsum of the right hand. Others were on the right side of the face, both elbows, both knees, left thigh, right lower leg. Both ulnar nerves were markedly enlarged, especially the right one.

In March, 1966, he was found to have a right mobile claw hand, with 3 moderate sized swellings in the greatly enlarged terminal branch of the radial nerve on the back of the right hand. There was also a small abscess of the lateral cutaneous nerve in the left forearm. Both superficial peroneal nerves were grossly enlarged, and each had two localised swellings in the lower part of the leg. On the right side the thickened nerve could be felt right across the dorsum of the foot to the first toe.

At operation, one of the swellings on the back of the hand contained glairy fluid, and there appeared to be a ganglion in the extensor tendon to the middle finger. The other 2 were nerve abscesses, containing frank and inspissated pus. Similar much larger abscesses were found in the legs, the left superficial peroneal being expanded into a wide ribbon above the ankle joint. Distal to this the nerve divided, and in 2 very small abscesses in one of the branches, smears of the pus showed 1 normal leprosy bacillus and a small group of acid fast granules. Smears from other sites showed no acid fast material. All wounds healed well without drainage. 


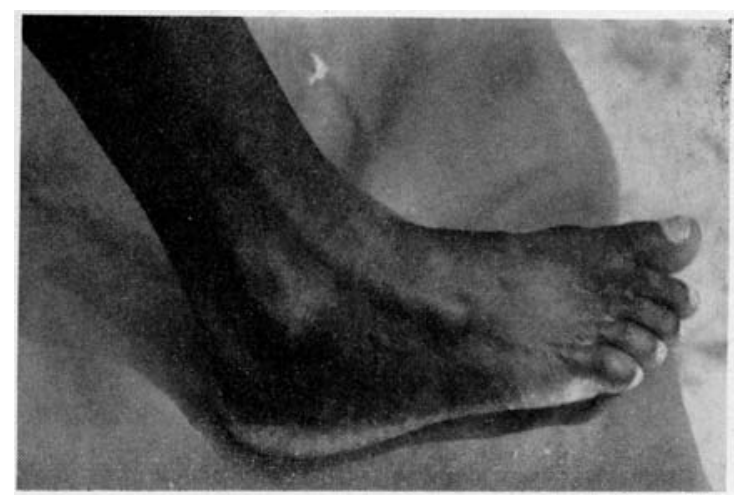

Nerve abscesses in R. superîcial peroneal nerve. Also had 2 abscesses in L. ulnar nerve at wrist, and in L. superficial peroneal nerve.

Patient 3

Patient 3 -This patient, a male aged 28 years, from the Chad Republic, had long-standing tuberculoid leprosy, but had only had treatment for a few months. He had flat, slightly hypopigmented lesions of right eyebrow, both forearms, back, left thigh and both legs. There was widespread nerve involvement, both ulnars, right median and left radial nerves being much enlarged and tender. The right popliteal and both superficial peroneal nerves were also much enlarged but not tender.

There were 2 abscesses of the left ulnar nerve on the dorsum of the hand, just distal to the ulnar styloid process. There were 2 in the superficial peroneal nerve on the dorsum of the right foot; 1 in the left lower leg, and 2 on the dorsum of the left foot. All of these were found to contain quite large amounts of creamy and yellow inspissated pus. The proximal one of the left wrist also contained some gelatinous necrotic material. Smears of the evacuated material showed small groups of acid fast granular material, but no recognisable bacilli. In this case also the wounds were closed without drainage, and healed quickly.

In addition to these 3 rather similar cases, the following patients with nerve abscesses have also been seen since 1963 .

June, 1963-A male adult with tuberculoid leprosy was referred for ulnar nerve decompression, and was found at operation to have an abscess in the nerve just above the elbow.

October, 1963-A young male adult with major tuberculoid leprosy, with 1 lesion of the right arm,

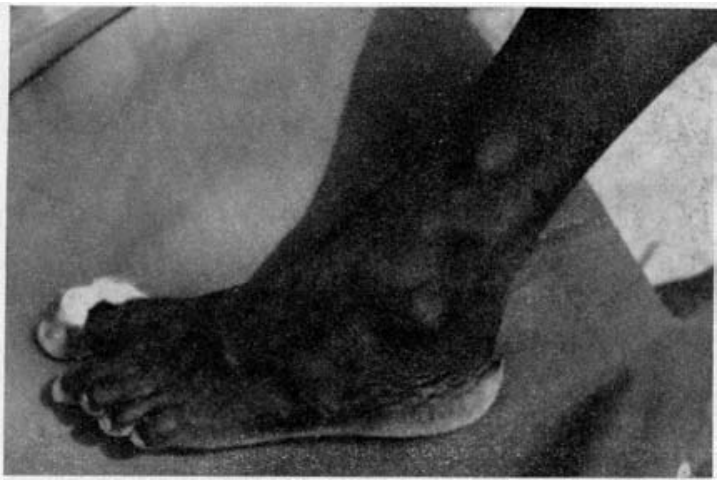

Nerve abscesses in L. superficial peroneal rierve. Also had 2 abscesses in L. ulnar at wrist, and in R. superficial peroneal nerve.

\section{Patient 3}

had 2 nerve abscesses of the ulnar nerve about midway between elbow and axilla, and $l$ in the medical cutaneous nerve in the same area.

May, 1966 - A male patient of 19 years was referred to the leprosarium with acute neuritis of the left popliteal nerve, which was grossly enlarged. He was found to have also great enlargement of the left superficial peroneal nerve, the posterior tibial nerve, and the saphenous nerve on the left. This last contained 3 small abscesses. The interesting feature of this case also was the fact that the only skin lesion which could be found was an apparently healed tuberculoid lesion of the dorsum and medial side of the left foot, extending upwards to just above the ankle. The skin over this area was shiny and atrophic.

June, 1966-A girl of 11 years, with reacting tuberculoid lesions, including several on the right forearm, hand and fingers, was referred to the Bornu Provincial Settlement for ulnar decompression. The nerve was much enlarged, hard and painful. At operation there was a small nodule on the outer aspect of the nerve, which contained a small amount of yellow pus, and a thin thread of this necrotic material continued upwards in nerve tissue for about 1 inch.

\section{SUMMARY}

Seven patients with nerve abscesses, some of them multiple, are described, from Plateau and Bornu Provinces of Nigeria, all of whom have been seen within the last 4 years. 